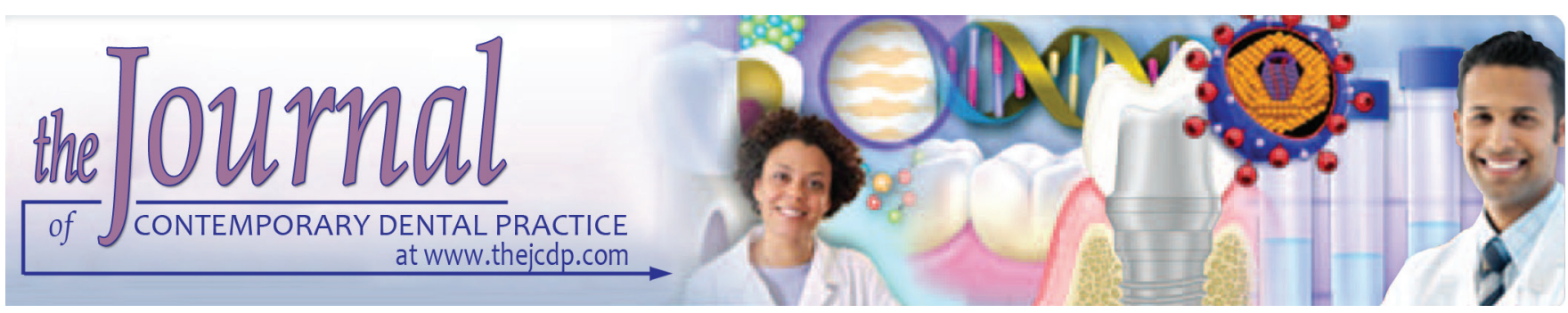

\title{
Sialometric and Sialochemical Changes in Morbidly Obese Patients before and after Bariatric Surgery
}

\author{
${ }^{1}$ Luiz CC Gambus, ${ }^{2}$ Aline CBR Johann, ${ }^{3}$ Patrícia VC Bettega, ${ }^{4}$ Edvaldo AR Rosa, ${ }^{5}$ Ivone MI Morimoto \\ ${ }^{6}$ Magda RR da Cruz, ${ }^{7}$ Luís S Nassif, ${ }^{8}$ Sérgio L Rocha, ${ }^{9}$ Sérgio 0 loshii, ${ }^{10}$ Andresa VS Vaz, ${ }^{11}$ Juliana AL Solyon \\ ${ }^{12}$ Francine Moraes, ${ }^{13}$ João A Brancher, ${ }^{14}$ Sérgio A Ignácio, ${ }^{15}$ Ana MTG Hardy
}

\section{ABSTRACT}

Aim: To evaluate the sialometric and sialochemical changes in morbidly obese patients before and after bariatric surgery.

Materials and methods: A total of 74 participants were divided into three groups paired by sex and age: (a) Experimental 1 (E1) —morbid obesity ( $n=40)$-according to the Fobi-Capella technique, corresponding to the individuals with a body mass index (BMI) of greater than $40 \mathrm{~kg} / \mathrm{m}^{2}$ prior to bariatric surgery; (b) Experimental 2 (E2) - the same individuals after surgery; and (c) control $(C)(n=34)$-individuals with a BMI of nearly $23 \mathrm{~kg} / \mathrm{m}^{2}$. The measure of salivary flow was carried out by collecting stimulated saliva. The $\mathrm{pH}$ was evaluated using the pocket $\mathrm{pH}$ meter, while the salivary buffer capacity (SBC) was determined by the titration method. Analyses of the salivary concentration of total proteins (TPs), amylase activity, urea, calcium $\left(\mathrm{Ca}^{++}\right)$, and glucose were evaluated using the calorimetric method.

Results: Group E1, as compared with group C, presented the highest $\mathrm{pH}$ levels $(p=0.03)$, amylase activity $(p=0.00)$, and calcium $(p=0.00)$. The opposite was observed for glucose $(p=0.00)$, TP $(p=0.04)$, and urea $(p=0.04)$. Group E2, as compared with group $C$, revealed higher levels of amylase $(p=0.00)$ and calcium $(p=0.00)$. The opposite was observed for $\operatorname{SBC}(p=0.01), \operatorname{PT}(p=0.00)$, and glucose $(p=0.00)$. Group E1, as compared with group E2, presented higher values of SBC

\footnotetext{
1-4,10-15Department of Dentistry, School of Life Sciences Pontifícia Universidade Católica do Paraná-PUCPR, Curitiba Paraná, Brazil

${ }^{5,6}$ Department of Nutrition, School of Life Sciences, Pontifícia Universidade Católica do Paraná-PUCPR, Curitiba, Paraná Brazil

${ }^{7-9}$ Department of Medicine, School of Medicine, Pontifícia Universidade Católica do Paraná-PUCPR, Curitiba, Paraná Brazil

Corresponding Author: Aline CBR Johann, Department of Dentistry, School of Life Sciences, Pontifícia Universidade Católica do Paraná-PUCPR, Curitiba, Paraná, Brazil, Phone: +554132712592, e-mail: aline.johann@pucpr.br
}

$(p=0.00)$ and urea $(p=0.00)$. The lowest values were found for calcium and urea $(p=0.03)$.

Conclusion: Both weight gain and bariatric surgery are risk factors for the oral condition, causing change in some important salivary components, such as TP, amylase, calcium, and glucose.

Clinical significance: This article is a valuable addition to the scientific literature, due to its novelty. There are no papers that show salivary alterations related to bariatric surgeries.

Keywords: Bariatric surgery, Body mass index, Morbid obesity, Obesity, Saliva.

How to cite this article: Gambus LCC, Johann ACBR, Bettega PVC, Rosa EAR, Morimoto IMI, da Cruz MRR, Nassif LS, Rocha SL, loshii SO, VazAVS, Solyon JAL, Moraes F, Brancher JA, Ignácio SA, Hardy AMTG. Sialometric and Sialochemical Changes in Morbidly Obese Patients before and after Bariatric Surgery. J Contemp Dent Pract 2018;19(7):756-761.

Source of support: Nil

Conflict of interest: None

\section{INTRODUCTION}

Obesity consists of an individual's excess body fat mass and it is a growing health care concern worldwide. ${ }^{1}$ Overweight affects approximately two billion people, and Brazil occupies the fifth position with approximately $52 \%$ of the population in overweight and obesity. ${ }^{2}$

The ideal esthetic body mass is a variable and historically cyclical concept, with an alternation between the abundant forms and the squalid and skinny models, according to the predominant cultural moment. Individuals are generally considered obese when they present a BMI (= weight $/$ height $^{2}$ ) of between 20 and $25 \mathrm{~kg} / \mathrm{m}^{2}$. Obese individuals can commonly be found with a BMI ranging between 30 and $40 \mathrm{~kg} / \mathrm{m}^{2}$, whereas morbidly obese individuals present a BMI of greater than $40 \mathrm{~kg} / \mathrm{m}^{2}{ }^{3}$

In developed and developing countries, the incidence of morbid obesity has increased significantly in recent 
decades, and is currently an important cause of early medical complications and premature deaths. ${ }^{4}$ Possible complications due to a morbid excess of weight include hypertension, coronary diseases, sleep apnea, hiatus hernia, hyperlipidemia, resistance to insulin, diabetes mellitus, menstrual irregularities, proteinuria, urinary incontinence, mycosis, cellulitis, osteoarthritis, alterations in sexual hormones, obstetric complications, mothers giving birth to oversized babies, among others. ${ }^{5}$ Since obesity is a limiting life condition, these people are frequently referred to abdominal surgeries, such as gastroplasty, for the treatment of obesity, after failure of other therapeutic modalities, such as diet and physical exercises. ${ }^{6}$

Data from the Brazilian Bariatric and Metabolic Surgery Society $(\mathrm{SBCBM})^{7}$ show that 93,500 surgeries were performed in Brazil in 2015. This number puts Brazil in the second place in the ranking of bariatric surgeries worldwide, behind only to the United States, with 196,000 procedures in the same year, according to the American Society for Metabolic and Bariatric Surgery (ASMBS). ${ }^{8}$

There are not enough studies describing the quantity and quality of saliva in morbidly obese persons, undergoing bariatric surgery. There is a hypothesis that obesity may interfere in the sialometry and sialochemistry of these people, since the whole endocrinological system is altered. In this sense, the present study proposed to study the salivary conditions of people undergoing bariatric surgery.

\section{MATERIALS AND METHODS}

The present study was approved by the Ethics Committee of the Pontific Catholic University of Paraná (PUCPR), under report number 2140. The individuals were informed about the purpose and other aspects of the study and they signed the informed consent form.

The sample population of this research consisted of 74 patients, 40 morbidly obese and 34 with a body mass within the normal standards. The morbidly obese individuals were selected from the "Stomach Reduction Surgery Program" at Irmandade of Santa Casa of Misericórdia of Curitiba, Paraná, Brazil, which included medical, nutritional, and dental follow-up. The exclusion criteria for this group included people who were not accepted for bariatric surgery, or who did not present any form of medical recommendation for this surgery.

The 74 participants were divided into three groups paired by sex and age. Experimental 1 (E1) morbid obesity ( $n=40$ )-according to the Fobi-Capella technique, corresponding to the individuals with a BMI greater than $40 \mathrm{~kg} / \mathrm{m}^{2}$ prior to bariatric surgery; Experimental 2 (E2) the same individuals after surgery; and control (C) ( $\mathrm{n}=34$ ) -individuals with a BMI of nearly $23 \mathrm{~kg} / \mathrm{m}^{2}$ with no medical history of cardiovascular disease, who did not have diabetes mellitus, and who were not taking prescribed medicine. The saliva collection of these individuals was performed in the hospital, in the Biochemical Laboratory III of PUCPR and in the dental clinic of PUCPR.

\section{Saliva Collection}

The total saliva samples were obtained by means of mechanical stimulation, using a piece of sterilized latex tube of a standard size $(1.5 \mathrm{~cm})$, with dental floss tied to it, to prevent the patient from swallowing or inhaling the latex.

The individuals were instructed to continuously chew the latex piece for 6 minutes. All saliva produced during the first minutes of stimulation was discarded. ${ }^{9}$ During the 5 subsequent minutes, the individuals spit saliva into a sterilized universal collector which had been previously labeled and weighed. ${ }^{10}$ The flasks containing the samples were secured and sent to the PUCPR Biochemical Laboratory, where they were processed. The time for the saliva collection occurred at night between 8:00 and 11:00 pm.

\section{Laboratory Procedures}

\section{Sialometric Evaluation}

The stimulated salivary flow (SSF) was obtained by means of the gravimetric method. The mass from the universal collector flask, after the collection of the saliva, was extracted from the same flask before collection. Considering that $1 \mathrm{gm}$ of mass is equal to $1 \mathrm{~mL}$ of saliva, ${ }^{11}$ the difference of the mass from the collector flask before and after the collection, divided by the time of 5 minutes, equals the SSF expressed in $\mathrm{mL} / \mathrm{min}$. To measure the mass of the universal collector before and after the collection, a Marte $^{\circledR}$, model AL 500, analytic scale (Marte ${ }^{\circledR}$, São Paulo, Brazil) was used.

\section{Sialochemical Evaluation}

The following variables were evaluated: $\mathrm{pH}, \mathrm{SBC}, \mathrm{TP}$, urea $(\mathrm{U})$, calcium $\left(\mathrm{Ca}^{++}\right)$, and glucose $(\mathrm{G})$, in addition to the $\alpha$-amylase activity.

Immediately after the collection of saliva, the salivary $\mathrm{pH}$ was determined through the use of a QUIMIS ${ }^{\circledR}$ Q400BD pocket $\mathrm{pH}$ meter (with right electrode) (QUIMIS ${ }^{\circledR}$, Diadema, SP). The SBC was determined by means of titration method with $1 \mathrm{~mL}$ of saliva added to $3 \mathrm{~mL}$ of hydrochloric acid $(\mathrm{HCl}) 5 \mathrm{mmol} / \mathrm{L}$. After 10 minutes, the final $\mathrm{pH}$ was checked using a pocket $\mathrm{pH}$ meter.

Before submitting it to biochemical tests, the saliva samples were centrifuged (3.000 gm for 10 minutes). Saliva concentrations of TPs and calcium were determined by means of the calorimetric method (Kits labtest 
Diagnóstica S.A., Lagoa Santa, Minas Gerais, Brazil). The enzymatic-calorimetric method was used to quantify the urea (mg/dL, enzymatic-calorimetric system to determine the Urea-CE-Labtest Diagnóstica S.A., Lagoa Santa, Minas Gerais, Brazil).

The amylase activity was determined by the calorimetric kinetic method (U/LSystem) to determine the amylase (Labtest Diagnóstica S.A., Lagoa Santa, Minas Gerais, Brazil). The quantification of glucose was carried out by the enzymatic system (mg/dL, Enzymatic system to determine the PAP Liquiform Glucose; Labtest Diagnóstica S.A., Lagoa Santa, Minas Gerais, Brazil). The absorbance reading was performed using the Thermo Spectronic Unicam $^{\circledR}$, Genesys $10 \mathrm{uV}$, spectrophotometer (Thermo Spectronic Unicam ${ }^{\circledR}$, New York, USA). The biochemical tests were carried out in triplicate for the saliva samples.

For this study, the collected data were analyzed statistically, using the Statistical Package for the Social Sciences program, version 18.0.

\section{Statistical Analysis}

From the objectives established in the present research, several questions or hypotheses were defined:

- Can a statistically significant difference in the average values of the variables of sex, age, SSF, pH, SBC, TP, amylase, urea, calcium, glucose, and BMI be observed in relation to the preoperative experimental and control groups?

- Can a statistically significant difference in the average values of the variables SSF, pH, SBC, TP, amlylase, urea, calcium, glucose, and BMI analyzed be observed in relation to the postoperative experimental and control groups?

- Can a statistically significant difference in the average values of the variables SSF, pH, SBC, TP, amylase, urea, calcium, glucose, and BMI analyzed be observed in relation to the preoperative and postoperative experimental groups?

The verification of the first and second hypothesis was performed with the aid of Student's t test for independent samples, given that the two groups analyzed presented a sample size of $n>30$, thus generating the recommendation for the use of a parametric Student's t test for independent samples. The adopted significance level was 0.05 . Similarly, the homogeneity of variance test among the groups was performed using the Levene homogeneity of variance test, in which the adopted significance level was also 0.05 . When the variable presented heterogeneity among the groups, Student's t test was used for independent samples, allowing for heterogeneous variances.

The verification of the third hypothesis was performed using the Student's t test for paired samples, given that the group of patients analyzed before and after the surgery presented a sample size of $n>30$, thus generating the recommendation for the use of the parametric Student's $\mathrm{t}$ test for dependent samples. The adopted significance level was 0.05 .

\section{RESULTS}

Forty obese patients were included in this study. The average age was of 33.4 years for group $C$ and 35.75 for groups E1 and E2, with no statistically significant difference $(p=0.05)$ among the average ages from groups $C, E 1$, and E2. The same occurred for the variable of $\operatorname{sex}(p=0.71)$, which confirms the pairing with age and sex. In group $C$, $23.54 \%$ were male and $76.47 \%$ were female, whereas in groups E1 and E2, 20\% were male and 80\% were female.

Group E1, as compared with group C, presented the highest $\mathrm{pH}$ levels $(\mathrm{p}=0.03)$, amylase activity $(\mathrm{p}=0.00)$, and calcium $(p=0.00)$. The opposite was observed for glucose $(p=0.00), T P(p=0.04)$, and urea $(p=0.04)$. Group $\mathrm{E} 2$, as compared with group $\mathrm{C}$, revealed higher levels of amylase $(p=0.00)$ and calcium $(p=0.00)$. The opposite was observed for SBC ( $p=0.01)$, PT $(p=0.00)$, and glucose $(p=0.00)$. Group E1, as compared with group E2, presented higher values of SBC $(p=0.00)$ and urea $(p=0.00)$. The lowest values were found for calcium and urea $(p=0.03)$.

Table 1 demonstrates the average values of the analyzed variables, both for the control and for the experimental groups.

Table 1: Average values of the saliva composition, sialometry, and BMI of the studied groups

\begin{tabular}{lllllll}
\hline & $C$ (average $\pm S D)$ & $E 1$ (average $\pm S D)$ & $E 2$ (average $\pm S D)$ & $\begin{array}{c}{ }^{*} C \times E 1 \\
(p \text {-value) }\end{array}$ & $\begin{array}{c}{ }^{* *} C \times E 2 \\
(p \text {-value) }\end{array}$ & $\begin{array}{c}{ }^{*} E 1 \times E 2 \\
(p \text {-value) }\end{array}$ \\
\hline SSF $(\mathrm{mL} / \mathrm{min})$ & $1.25 \pm 0.50$ & $1.22 \pm 1.08$ & $1.31 \pm 0.69$ & 0.06 & 0.08 & 0.73 \\
pH & $7.19 \pm 0.31$ & $7.24 \pm 0.58$ & $7.24 \pm 0.39$ & 0.03 & 0.46 & 0.90 \\
SBC & $6.35 \pm 0.60$ & $6.75 \pm 0.60$ & $5.8 \pm 1.02$ & 0.72 & 0.01 & 0.00 \\
TP $(\mathrm{g} / \mathrm{dL})$ & $0.33 \pm 0.35$ & $0.24 \pm 0.17$ & $0.26 \pm 0.08$ & 0.04 & 0.00 & 0.66 \\
Amylase $(\mathrm{U} / \mathrm{dL})$ & $740.13 \pm 31.18$ & $778.32 \pm 13.00$ & $773.83 \pm 10.25$ & 0.00 & 0.00 & 0.21 \\
Urea $(\mathrm{mg} / \mathrm{dL})$ & $29.38 \pm 10.00$ & $25.63 \pm 16.05$ & $13.05 \pm 9.66$ & 0.04 & 0.77 & 0.00 \\
$\mathrm{Ca}^{++}(\mathrm{mg} / \mathrm{dL})$ & $0.78 \pm 0.80$ & $1.87 \pm 1.95$ & $2.90 \pm 1.40$ & 0.00 & 0.00 & 0.03 \\
Glucose $(\mathrm{mg} / \mathrm{dL})$ & $62.5 \pm 47.19$ & $20.85 \pm 25.56$ & $18.43 \pm 19.08$ & 0.00 & 0.00 & 0.95 \\
BMl $\left(\mathrm{kg} / \mathrm{m}^{2}\right)$ & $25.20 \pm 3.41$ & $47.51 \pm 7.19$ & $36.35 \pm 7.49$ & 0.00 & 0.00 & 0.00 \\
\hline
\end{tabular}

*Student's t test for independent samples; **Student's t test for paired samples; SD: Standard deviation 


\section{DISCUSSION}

Saliva, which contains a large number of organic and inorganic compounds, ${ }^{12}$ can be seen as a very important health indicator. ${ }^{13}$ Salivary secretion is controlled by the autonomic nervous system through receptors present in the salivary glands. ${ }^{14}$ Studies show that medicine and diseases can affect the function of salivary glands regarding the quality and quantity of saliva secreted. ${ }^{15}$

Obesity is a disease that leads to physiological, anatomical, and endocrinological changes. ${ }^{16-18}$ Bariatric surgery is the only proven effective treatment for weight loss, in persons with severe obesity (BMI $\geq 35 \mathrm{~kg} / \mathrm{m}^{2}$ ) and it has a profound effect on metabolism and nutritional status from the first days after the procedure, even before significant weight loss has been achieved. ${ }^{19}$

This is the first study to evaluate the condition of saliva in morbidly obese patients before and after bariatric surgery. It observed sialochemical, but not sialometric changes upon comparing: (a) The control group of preoperative patients: $\mathrm{pH}, \mathrm{TP}, \alpha$-amylase, urea, $\mathrm{Ca}^{++}$, and glucose; (b) the control group of postoperative patients: SBC, PT, $\alpha$-amylase, $\mathrm{Ca}^{++}$, and glucose; and (c) preoperative and postoperative patients: $\mathrm{SBC}$, urea, and $\mathrm{Ca}^{++}$. This indicates that obesity and bariatric surgery can interfere with the salivary condition.

The SSF demonstrates the amount of saliva released in a given period of time; the normal mean value for SSF described in the literature is $2 \mathrm{~mL} / \mathrm{min}$ (1.0 to 3.0). ${ }^{20}$ People with hyposalivation present a value of lower than $1 \mathrm{~mL} / \mathrm{min}$. Xerostomia and/or hyposalivation are (is) related to the lack of hydration or systemic conditions. In addition, psychological factors and medicine may alter the salivary flow. ${ }^{15}$

The SSF values found in all groups of this research are similar to the normal average. In this study, there were no differences in SSF when comparing all groups. This means that neither obesity nor the surgery itself interferes in SSF. Furthermore, obese people, before and after surgery, are monitored by a nutrition specialist, who instructs them to drink sufficient quantities of water to maintain good hydration. Pannunzio et $\mathrm{al}^{13}$ also found no difference in SSF among overweight, obese, and control school children group.

An inverse correlation can be observed between the $\mathrm{pH}$ of saliva and dental decalcification: the lower the $\mathrm{pH}$, the greater the decalcification. The normal $\mathrm{pH}$ of saliva is 6.5 to 7.5, which indicates that saliva is usually acidic; however, salivary $\mathrm{pH}$ varies with salivary flow, which may change from 5.3 to $7.8 .^{20}$ In this study, the $\mathrm{pH}$ values observed in all groups were within the normal range, as described earlier. Although a higher $\mathrm{pH}$ was observed in group E1, when compared with group $\mathrm{C}$, this variation was small and may not have a clinical impact. This slight difference in $\mathrm{pH}$ may be justified by the higher calcium concentration observed in the experimental group. Pannunzio et $\mathrm{al}^{13}$ found that the salivary $\mathrm{pH}$ of the group of obese children showed no differences when compared with the control children group.

The SBC neutralizes salivary acidity. The oral acids, originated from the fermentation of carbohydrates by the cariogenic bacteria of the mouth, propitiate dental caries. It is known that SBC $\geq 5$ is considered adequate; i.e., it meets the organism's physiological needs. ${ }^{21}$ The present study observed that the values from all groups were suitable (greater than 5); therefore, although a lower SBC value could be observed in the E2 group, as compared with groups $C$ and $E 1$, this most likely does not interfere in the saliva's buffering action.

Saliva contains immunological and nonimmunological proteins with antibacterial properties. The normal TP values correspond to 0.11 to $0.2 \mathrm{gm} / \mathrm{dL}{ }^{22}$ The present study identified a higher TP value than normal values in both the control and experimental groups. A higher average TP value was observed in the control group as compared with the experimental groups. Contrary to the results of this research, Pannunzio et $\mathrm{al}^{13}$ found a higher TP value in the saliva of obese children than in the control group. Further studies should be developed to elucidate these findings.

The chemical digestion of food begins with the secretion of salivary amylase and a very small amount of salivary lipase. ${ }^{23}$ The salivary amylase is an enzyme that accelerates the hydrolysis of starch and glycogen. The amylase found in the blood is generally pancreatic, ${ }^{24}$ whereas the salivary amylase produced by the acinar cells of the salivary glands is exocrine. ${ }^{25}$ Normal $\alpha$-amylase values range from 11 to $304 \mathrm{U} / \mathrm{dL}$. In the present study, values that were much higher than these were found in all groups. A higher value of $\alpha$-amylase was observed in the experimental groups when compared with the control group.

According to Rohleder and Nater, ${ }^{23}$ there is evidence that basal amylase tends to be higher in populations with high carbohydrate intake and that the salivary amylase rises quickly with physical exercise. Nevertheless, the results of this study are not justified. Given that the people involved in this research were hospitalized and, therefore, had no exercise, they were fed with a balanced diet, with the saliva collected after 1 hour of fasting. A subsequent study on the diet of the assessed population could explain these levels of $\alpha$-amylase.

Urea acts as another buffer in saliva, as it is an organic compound that causes rapid increase in the $\mathrm{pH}$ of the biofilm by releasing ammonia and carbon dioxide. The normal value of urea is from 17 to $41 \mathrm{mg} / \mathrm{dL} .^{26} \mathrm{In}$ 
the present study, normal values could be observed in groups C and E1. However, a mean urea value of lower than the normal values could be observed in group E2. Furthermore, patients who underwent surgery, as compared with the preoperative group, presented a reduction in urea. These findings can be explained by changes in the eating habits in general and, consequently, a reduction in the intake of animal protein by patients undergoing surgery. $^{26}$

Many inorganic components are eliminated by the saliva, but among the most important are calcium cations $\left(\mathrm{Ca}^{++}\right)$, whose concentration is highly variable and dependent upon salivary flow. ${ }^{27}$ The concentration of salivary $\mathrm{Ca}^{++}$is essential in maintaining the integrity of the teeth as well as the demineralization and remineralization modulation. ${ }^{28}$ The normal concentration of $\mathrm{Ca}^{++}$ in stimulated saliva is $6 \mathrm{mg} / \mathrm{dL}$, and its concentration is not affected by diet. ${ }^{26}$ Concentrations of $\mathrm{Ca}^{++}$lower than the reference value were observed in all groups of this research. Further studies should be developed to elucidate this finding. Both experimental groups presented higher concentrations of calcium than control. Moreover, an increased concentration of $\mathrm{Ca}^{++}$could be identified in E2, as compared with E1. One possible explanation for this increase in $\mathrm{Ca}^{++}$saliva may well be related to progressive weight loss in these people before surgery, considering that they undergo a preparation process at this stage, in which initial weight loss is important; the body, with its reduced weight, now perceives that it has no need for such a reinforced bone structure. This weight loss is accentuated after surgery.

The levels of $\mathrm{Ca}^{++}$in the body are regulated by the endocrine system and kidneys. In the kidneys, the $\mathrm{Ca}^{++}$ ion is filtered by the glomerulus and reabsorbed by the renal tubules. The endocrine portion is regulated by the parathyroid glands which, in the presence of low plasma levels of $\mathrm{Ca}^{++}$, increase production of the parathyroid hormone (PTH), or parathrin, promoting and raising the calcium levels through the activation of osteoclasts and the proliferation of bone erosion. ${ }^{29}$ Thus, with the loss of bone mass, $\mathrm{Ca}^{++}$would be moving toward the body fluid, thus justifying its increase in saliva. ${ }^{30}$

Unlike the results of this study, Pannunzio et $\mathrm{al}^{13}$ found that the concentration of salivary calcium in children, as compared with the obesity control group, showed no differences. In the future, more in-depth studies should be conducted involving salivary calcium and plasma levels of $\mathrm{Ca}^{++}$to better understand this finding.

Normal levels of glucose in the saliva range from 0.5 to $1 \mathrm{mg} / \mathrm{dL}$. These values did not significantly affect oral health or promote microorganism growth. ${ }^{30}$ Normal glucose values are variable, possibly due to different methodologies and sample selection criteria. The present study found that, when compared with normal values, a higher glucose concentration in all groups could be observed. This higher glucose concentration favors the proliferation of microorganisms and their colonization on teeth and oral mucosa. A lower glucose concentration in the experimental groups, as compared with the control group, could be observed. Considering that the morbidly obese persons involved in the present study were preparing for bariatric surgery, and were therefore placed under a strict diet, their mean glucose levels, when compared with the control group, proved to be low. This fact is most likely due to the new stance on food education, which restricts the intake of sugar within one's diet. This food reduction also occurs in patients after stomach reduction surgery.

\section{CONCLUSION}

Weight gain alters sialochemistry, i.e., some important salivary components, such as amylase, urea, glucose, calcium, and TPs. Patients submitted to bariatric surgery compared with the control presented a correction in the $\mathrm{pH}$ and urea variables, in addition to the increase in SSF.

It can be concluded that excessive weight gain produces a significant and negative influence on sialochemistry, but produces a larger SSF, which illustrates that no hyposalivation occurs after surgery. Therefore, there is a need for special care when faced with a growing number of morbidly obese patients and bariatric surgeries.

\section{REFERENCES}

1. Gao F, Wang ZJ, Shen H, Yang SW, Nie B, Zhou YJ. Impact of obesity on mortality in patients with diabetes: meta-analysis of 20 studies including 250,016 patients. J Diabetes Investig 2018 Jan;9(1):44-54.

2. Campos JM. The Brazilian Society of Bariatric and Metabolic Surgery-SBCBM-prioritizes encouraging of scientific production. Arq Bras Cir Dig 2015 Dec;28(Suppl 1):1.

3. Brouwer CA, Gietema JA, Vonk JM, Tissing WJ, Boezen HM, Zwart N, Postma A. BMI and annual increase of BMI in longterm childhood cancer survivors; relationship to treatment. Support Care Cancer 2012 Feb;20(2):311-318.

4. Ng M, Fleming T, Robinson M, Thomson B, Graetz N, Margono C, Mullany EC, Biryukov S, Abbafati C, Abera SF, et al. Global, regional, and national prevalence of overweight and obesity in children and adults during 1980-2013: a systematic analysis for the Global Burden of Disease Study 2013. Lancet 2014 Aug;384(9945):766-781.

5. Żurawiński W, Sokołowski D, Krupa-Kotara K, Czech E, Sosada K. Evaluation of the results of treatment of morbid obesity by the endoscopic intragastric balloon implantation method. Wideochir Inne Tech Maloinwazyjne 2017 Mar;12(1): 37-48.

6. Lopez-Nava G, Galvão MP, Bautista-Castaño I, FernandezCorbelle JP, Trell M, Lopez N. Endoscopic sleeve gastroplasty for obesity treatment: two years of experience. Arq Bras Cir Dig 2017 Jan-Mar;30(1):18-20. 
7. Brazilian Bariatric and Metabolic Surgery Society. Brazilian society of bariatric surgery supports targets to contain obesity and proposes consumer alert seal. Brazil: SBCBM; 2017. [Cited 2017 May 27]. Available from: http:/ / sbcbm.org.br/wordpre ss=surgeries+bariatrics+done+in+brazil + in +2015 .

8. American Society for Metabolic and Bariatric Surgery. Estimate of bariatric surgery numbers, 2011-2016. Gainesville (FL): ASMBS; 2017. [Cited 2017 Mar 21]. Available from: http:// asmbs.org/resources/estimate-of-bariatric-surgery-numbers.

9. Dawes C. Physiological factors affecting salivary flow rate, oral sugar clearance, and the sensation of dry mouth in man. J Dent Res 1987 Feb;66(Spec No):648-653.

10. Mörnstad H, Von Knorring L, Forsgren L, Holmgren S. Acute effects of some different antidepressant drugs on saliva composition. Neuropsychobiology 1986;15(2):73-79.

11. Banderas-Tarabay JA, Gonzáles-Begne M,Sanchez-Garduno M, Millán-Cortéz E, López-Rodríguez A, Vilchis-Velázquez A. The flow and concentration of proteins in human whole saliva. Salud Publica Mex 1997 Sep-Oct;39(5):433-441.

12. Actis AB, Perovic NR, Defagó D, Beccacece C, Eynard AR. Acid profile of human saliva: a possible indicator of dietary fat intake. Arch Oral Biol 2005 Jan;50(1):1-6.

13. Pannunzio E, Amancio OM, Vitalle MS, Souza DN, Mendes FM, Nicolau J. Analysis of stimulated whole saliva in overweight and obese school children. Rev Assoc Med Bras (1992) 2010 Jan-Feb;56(1):32-36.

14. Castagnola M, Scarano E, Passali GC, Messana I, Cabras T, Iavarone F, Di Cintio G, Fiorita A, De Corso E, Paludetti G. Salivary biomarkers and proteomics: future diagnostic and clinical utilities Biomarkers e proteomica salivari: prospettive future cliniche e diagnostiche. Acta Otorhinolaryngol Ital 2017 Apr;37(2):94-101.

15. Grégio AM, Durscki JR, Lima AA, Machado MA, Ignácio SA, Azevedo LR. Association of amitriptyline and diazepam on the histomorphometry of rat parotid glands. Pharmacol Online 2006;2:96-108.

16. Kohli R, Stefater MA, Inge TH. Molecular insights from bariatric surgery. Rev Endocr Metab Disord 2011 Sep;12(3):211-217.

17. Chauhan V, Vaid M, Gupta M, Kalanuria A, Parashar A. Metabolic, renal, and nutritional consequences of bariatric surgery: implications for the clinician. South Med J 2010 Aug;103(8):775-783, quiz 784-785.
18. Tenovuo J. Salivary parameters of relevance for assessing caries activity in individuals and populations. Community Dent Oral Epidemiol 1997 Feb;25(1):82-86.

19. Krasse, B. Caries risk: a practical guide for assessment and control. Chicago (IL): Quintessence Pub Co.; 1985. p. 113.

20. Kobus A, Kierklo A, Zalewska A Kuźmiuk A, Szajda SD, Ławicki S, Bagińska J. Unstimulated salivary flow, $\mathrm{pH}$, proteins and oral health in patients with juvenile idiopathic arthritis. BMC Oral Health 2017 Jun;17(1):94.

21. Bornhorst GM, Gouseti O, Wickham MS, Bakalis S. Engineering digestion: multiscale processes of food digestion. J Food Sci 2016 Mar;81(3):R534-R543.

22. Humphrey SP, Williamson RT. A review of saliva: Normal composition, flow, and function. J Prosthet Dent 2001 Feb;85(2):162-169.

23. Rohleder N, Nater UM. Determinants of salivary alfaamylase in humans and methodological considerations. Psychoneuroendocrinology 2009 May;34(4):469-485.

24. Edgar WM. Saliva: its secretion, composition and functions. Br Dent J 1992 Apr;172(8):305-312.

25. Gao X, Jiang S, Koh D, Hsu CY. Salivary biomarkers for dental caries. Periodontol 20002016 Feb;70(1):128-141.

26. Abou Neel EA, Aljabo A, Strange A, Ibrahim S, Coathup M, Young AM, Bozec L, Mudera V. Demineralizationremineralization dynamics in teeth and bone. Int J Nanomed 2016 Sep;11:4743-4763.

27. Hebert SC, Brown EM, Harris HW. Role of the Ca (2+)-sensing receptor in divalent mineral ion homeostasis. J Exp Biol 1997 Jan;200(Pt 2):295-302.

28. Bristow SM, Gamble GD, Horne AM, Reid IR. Dietary calcium intake and rate of bone loss in men. Br J Nutr 2017 May;117(10):1432-1438.

29. Panchbhai AS, Degwekar SS, Bhowte RR. Estimation of salivary glucose, salivary amylase, salivary total protein and salivary flow rate in diabetics in India. J Oral Sci 2010 Sep;52(3):359-368.

30. Smith AE, Annesi JJ, Walsh AM Lennon V, Bell RA. Association of changes in self-efficacy, voluntary physical activity, and risk factors for type 2 diabetes in a behavioral treatment for obese preadolescents: a pilot study. J Pediatr Nurs 2010 Oct;25(5):393-399. 